\title{
Variation of iStent Procedure Rates by State in Response to the COVID-19 Pandemic
}

\author{
Kelly Vogel $\mathbb{D}^{\prime}$, Cole N Rojas', Angelo P Tanna', Dustin D French $\mathbb{D}^{1-4}$ \\ 'Department of Ophthalmology, Northwestern University Feinberg School of Medicine, Chicago, IL, USA; 'Department of Medical Social Science, \\ Northwestern University Feinberg School of Medicine, Chicago, Illinois, USA; ${ }^{3}$ Center for Health Services and Outcomes Research, Northwestern \\ University Feinberg School of Medicine, Chicago, IL, USA; ${ }^{4}$ Veterans Affairs Health Services Research and Development Service, Chicago, IL, USA \\ Correspondence: Dustin D French, Tel +| 813789 9382, Fax +| 312695 3652, Email dustin.french@northwestern.edu
}

\section{Introduction}

Geospatial analysis is a useful tool for understanding variations in the way healthcare is delivered. A study by Welch et al showed over a two-fold difference in Medicare expenditures per beneficiary when comparing the highest spending metropolitan area, Miami, to the lowest spending metropolitan area, San Francisco. ${ }^{1}$ Geospatial variations are observed specifically in ophthalmology as well, as Kauh et al described with cataract surgery in 2016. This study demonstrated a 5 -fold difference in age-standardized cataract surgeries between the highest and lowest utilization communities. ${ }^{2}$ Variations in glaucoma procedures are of particular interest, given that Medicare spending on glaucoma surgeries has increased from $\$ 52 \mathrm{M}$ in 2007 to $\$ 180 \mathrm{M}$ in 2017 , which was driven mostly by increased utilization of iStent, a small drainage device placed into the trabecular meshwork through direct visualization of the anterior chamber angle. ${ }^{3}$ Unsurprisingly, iStent adoption is not an exception to geospatial variability. Large regional differences have been observed in the rate at which states incorporated iStent into clinical practice. These differences were associated with demographic factors of the individual states, including differences in gender and age distribution. ${ }^{4}$

The COVID-19 pandemic changed the way ophthalmology is practiced in the United States. Even some emergent and urgent ophthalmic procedures, such as retinal detachment repair, saw decreasing rates of utilization early in the pandemic. ${ }^{5}$ In our work, we sought to better understand how the COVID-19 pandemic impacted rates of iStent use on the national and state level by utilizing the 2015 to 2020 Medicare databases and geospatial mapping technology.

\section{Materials and Methods}

Data Source and Ethics

We used a Medicare ambulatory surgical claims limited dataset for 2015 through 2020 (January 1st, 2015, to December 31st, 2020), which consists of records of procedures performed on the enrollees in each state based on the Healthcare Common Procedure Coding System for each calendar year. This study was deemed exempt from requiring IRB approval by Northwestern's University's IRB office (STU0007111), given the study was determined not to constitute as human subjects research. Use of the Medicare data was approved by the Centers for Medicare and Medicaid Services of the Department of Health and Human Services.

\section{Analysis}

Pivot tables were created to sum iStent procedures per year on the state and national levels. The percent change in iStent procedures on a national level on a year-to-year basis between years of 2015 through 2019 was calculated, averaged, and compared to the percent change in procedures from 2019 to 2020 using a $t$-test.

Additionally, the percent change in iStent procedures on the state level from 2019 to 2020 was calculated. A geospatial map of the percent change in iStent procedures by state was created using ArcGIS and ArcMap version 10.3 software (Esri). SAS version 9.4 (SAS Institute Inc) was used for data calculations. 


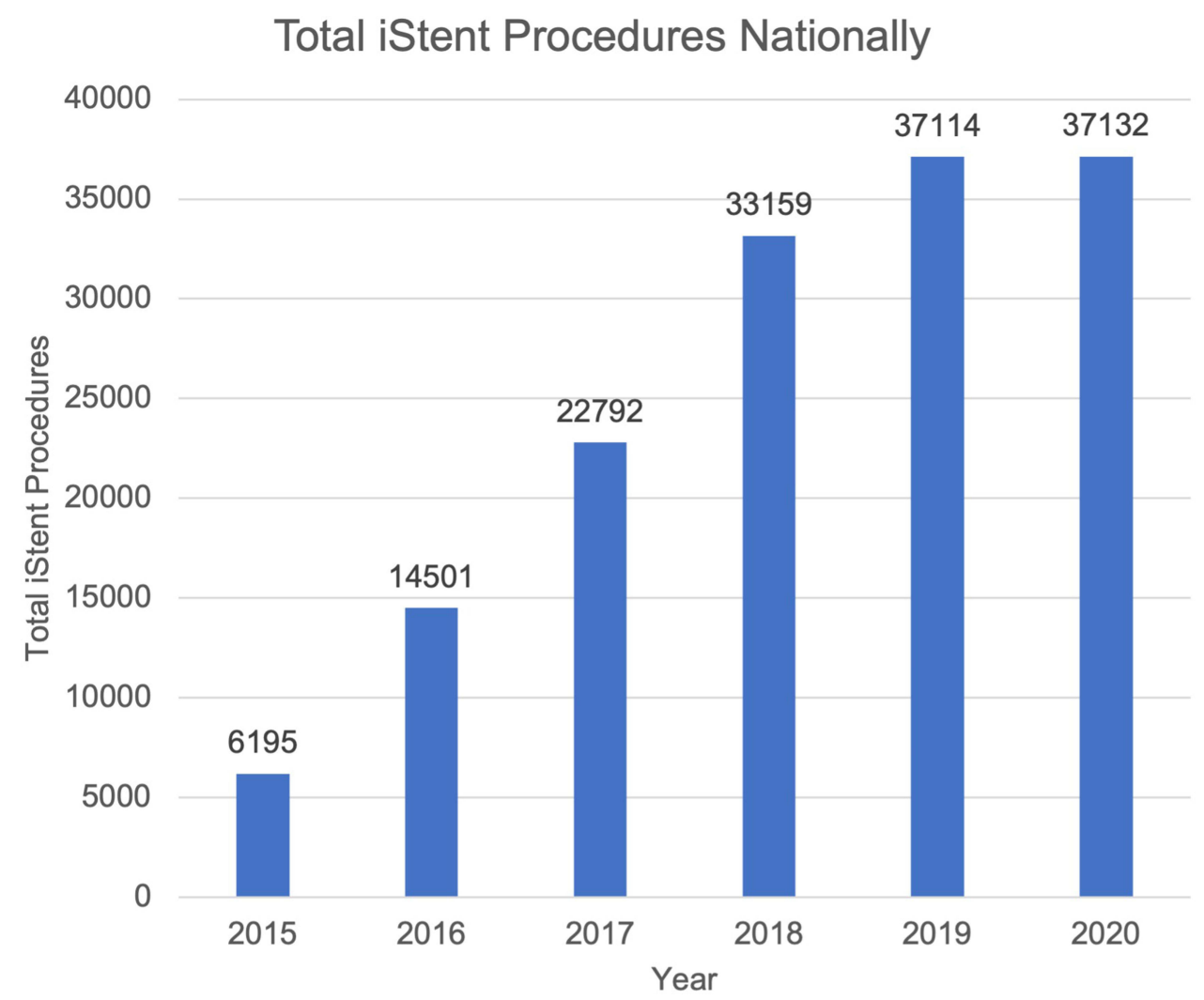

Figure I Total iStent procedures in the United States 20I5-2020.

\section{Results}

The total iStent procedures on a yearly basis from 2015 to 2020 in the United States can be seen in Figure 1. Most notably, there were 37,114 iStent procedures performed in 2019 and 37,132 iStent procedures performed in 2020. The average annual growth rate (percent change) from 2015 to 2019 was $43.1 \%$ and from 2019 to 2020 was $0.05 \%(\mathrm{P}<0.01)$. The percent difference in iStent procedures from 2019 to 2020 varied widely between states, as seen in Figure 2. Notably, Washington, South Carolina, and Montana saw over 100\% increases in iStent procedure rates, whereas Connecticut, Hawaii, and New Mexico saw decreases of over $25 \%$.

\section{Discussion}

Previous research has demonstrated the rapid adoption of iStent, and our work similarly demonstrates iStent utilization increased almost 6-fold from 2015 to 2019 with procedure rates consistently increasing each year. ${ }^{4}$ However, this trend failed to be upheld from 2019 to 2020 when the number of iStent procedures performed essentially leveled off. Coinciding with this shift was the onset of the COVID-19 pandemic. This trend is in congruence with previous survey work in the UK that showed physicians altered their glaucoma surgery practice to reduce surgeries performed, especially trabeculectomies. ${ }^{6}$ Another study in Brazil demonstrated similar trends of decreased utilization of glaucoma outpatient clinical visits and visual field exams performed. ${ }^{7}$

While there was a leveling off of iStent procedures nationally, there was a large amount of variation on a state-bystate basis, as displayed in Figure 2. While variation between states in iStent use has been observed in the past, our work demonstrates patterns that are different than those observed by Lee et al for iStent uptake for the years 2012 to 2017. For example, in Lee et al, it was observed that the three states with the highest uptake of iStent included New Jersey, South Carolina, and Iowa, while our work showed Washington, South Carolina, and Montana were the three states with the greatest growth in iStent procedures from 2019 to $2020 .^{4}$ 


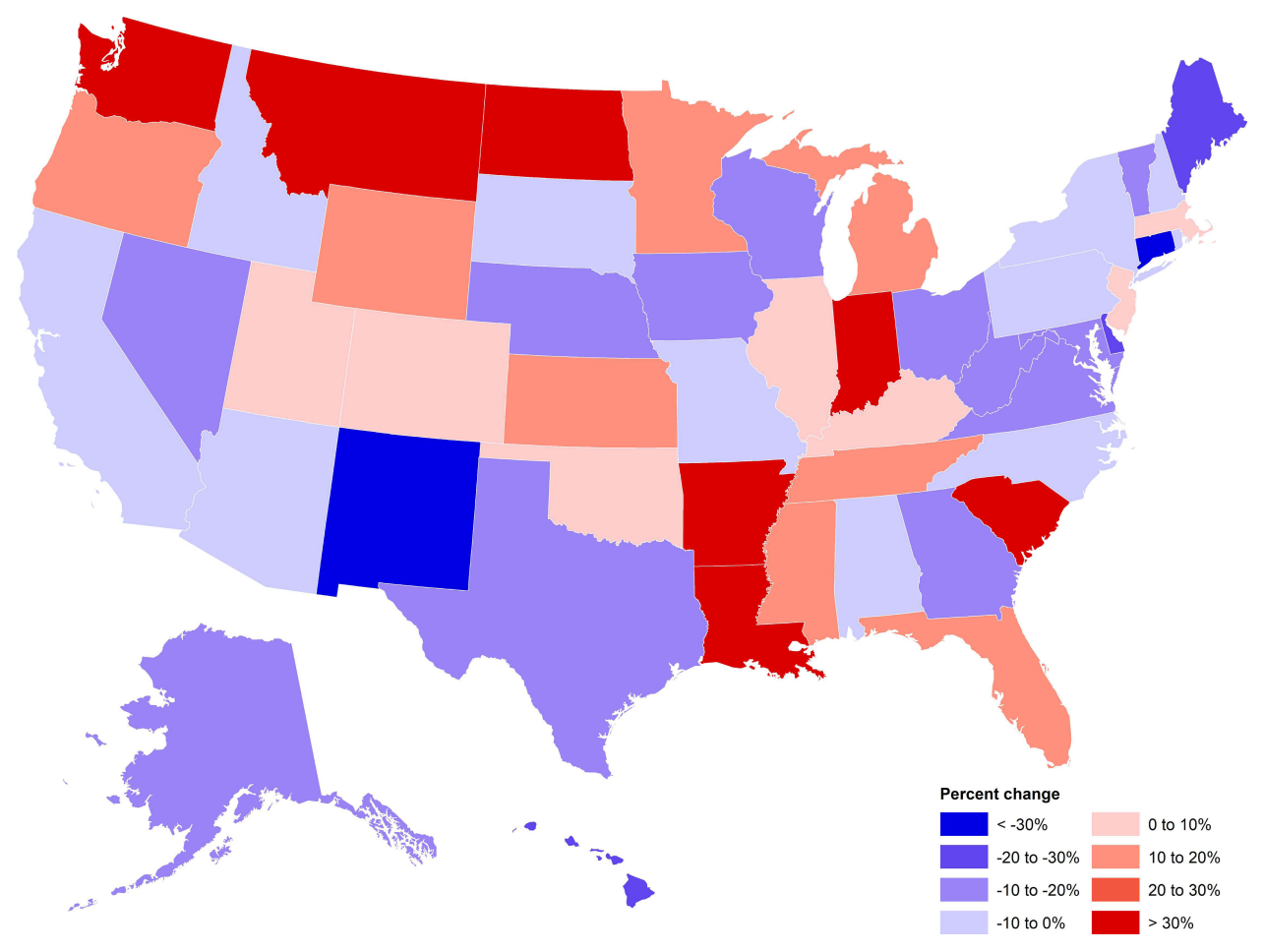

Figure 2 Heatmap of percent change in iStent procedure by state 2019 to 2020 .

Our work is limited by Medicare data only being available each calendar year level, which does not allow us to explore on how the COVID-19 pandemic impacted surgery trends on a more specific monthly basis as the pandemic expanded in the spring of 2020. Furthermore, our work does not control for other potential factors impacting the number of iStent procedures performed, such as changes in surgeon preference for iStent and changes in cataract surgery levels, as iStent implantation usually occurs in conjunction with cataract surgery.

\section{Conclusion}

Overall, the timing of the COVID-19 pandemic was correlated with a deviation from prior iStent trends, given that iStent procedure utilization increased on a yearly basis prior to the COVID-19 pandemic but remained essentially unchanged between 2019 and 2020. Our work also shows variation in utilization trends on a state-by-state basis. We hope that this analysis provides a first step in understanding the factors that drive surgeon preference for iStent in the era of COVID-19 as well as a template for better understanding how other ophthalmic procedures were affected by the COVID-19 pandemic.

\section{Acknowledgments}

We thank Karl Y. Bilimoria, MD, MS, of the Surgical Outcomes Quality Improvement Center at Northwestern University, who assisted in obtaining Medicare data, and Kelsey Rydland, Data Services Librarian, Northwestern University Libraries, who assisted in creating the geospatial map. This submission has not been published or posted anywhere previously and is not simultaneously being considered for any other publication.

\section{Funding}

This research was supported by an Unrestricted Departmental Grant from Research to Prevent Blindness, NY (French, Tanna). This research was also supported by the Northwestern Open Access Fund. The funders had no role in the design and conduct of the study; collection, management, analysis, and interpretation of the data; preparation, review, or approval of the manuscript; and decision to submit the manuscript for publication. 


\section{Disclosure}

Ms Kelly Vogel reports a grant from Northwestern Open Access Fund, during the conduct of the study. Dr Angelo P Tanna reports personal fees/grants from Sandoz, Zeiss, Ivantis, Google, and Illinois Society for the Prevention of Blindness, outside the submitted work. The authors report no other conflicts of interest in this work.

\section{References}

1. Welch WP, Miller ME, Welch HG, Fisher ES, Wennberg JE. Geographic variation in expenditures for physicians' services in the United States. N Engl J Med. 1993;328(9):621-627. doi:10.1056/NEJM199303043280906

2. Kauh CY, Blachley TS, Lichter PR, Lee PP, Stein JD. Geographic variation in the rate and timing of cataract surgery among US communities. JAMA Ophthalmol. 2016;134(3):267-276. doi:10.1001/jamaophthalmol.2015.5322

3. Shalaby WS, Jia J, Katz LJ, Lee D. iStent inject: comprehensive review. J Cataract Refract Surg. 2021;47(3):385-399. doi:10.1097/j. jers. 0000000000000325

4. Lee JH, Ma AK, Warren JL, Teng CC. Impact of iStent micro-bypass shunt on medicare part B glaucoma surgical expenditure. Ophthalmol Glaucoma. 2021;4(2):131-138. doi:10.1016/j.ogla.2020.05.004

5. Breazzano MP, Nair AA, Arevalo JF, et al. Frequency of urgent or emergent vitreoretinal surgical procedures in the United States during the COVID-19 pandemic. JAMA Ophthalmol. 2021;139(4):456. doi:10.1001/jamaophthalmol.2021.0036

6. Holland LJ, Kirwan JF, Mercieca KJ. Effect of COVID-19 pandemic on glaucoma surgical practices in the UK. Br J Ophthalmol. 2021. doi:10.1136/ bjophthalmol-2021-319062

7. Ayub G, de Vasconcelos JP, Costa VP. The impact of Covid-19 in the follow-up of glaucoma patients in a tertiary center: a comparison between pre-pandemic and pandemic periods. Clin Ophthalmol. 2021;15:4381-4387. doi:10.2147/OPTH.S334147

\section{Publish your work in this journal}

Clinical Ophthalmology is an international, peer-reviewed journal covering all subspecialties within ophthalmology. Key topics include: Optometry; Visual science; Pharmacology and drug therapy in eye diseases; Basic Sciences; Primary and Secondary eye care; Patient Safety and Quality of Care Improvements. This journal is indexed on PubMed Central and CAS, and is the official journal of The Society of Clinical Ophthalmology (SCO). The manuscript management system is completely online and includes a very quick and fair peer-review system, which is all easy to use. Visit http://www. dovepress.com/testimonials.php to read real quotes from published authors.

Submit your manuscript here: https://www.dovepress.com/clinical-ophthalmology-journal 